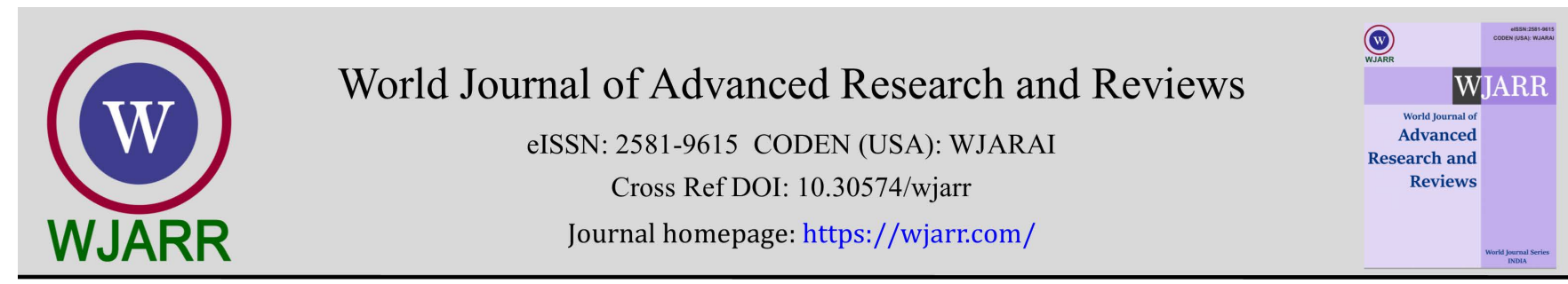

(REview ARTICLE)

Check for updates

\title{
Vietnam economic outlook during the COVID-19 pandemic: A review
}

\author{
Nguyen Thi Van Anh ${ }^{1,{ }^{*}}$ and Dang Thi Hoa ${ }^{2}$ \\ ${ }^{1}$ Faculty of Business Management, Hanoi University of Industry, No 298 Cau Dien Street, Minh Khai Ward, Bac Tu Liem \\ District, Hanoi City, Vietnam. \\ ${ }^{2}$ Faculty of Economics, National Economics University, No 207 Giai Phong Road, Hai Ba Trung District, Hanoi, Vietnam
}

World Journal of Advanced Research and Reviews, 2021, 10(03), 229-232

Publication history: Received on 01 May 2021; revised on 08 June 2021; accepted on 11 June 2021

Article DOI: https://doi.org/10.30574/wjarr.2021.10.3.0266

\begin{abstract}
This study reviews the effects of the COVID-19 outbreak on the development of Vietnam's economy and the change of the Vietnam government's policies to adapt to critical challenges. The COVID-19 pandemic seriously has been impacting all economies around the world including Vietnam. To bring the pandemic under control, Vietnam performed the same strategies that had been successful in ending earlier outbreaks: targeted lockdowns, travel bans, business closures, mass quarantines, and widespread testing. However, the Vietnam government has also flexibly taken decisive steps to reduce both the health and economic fallout. Vietnamese economy increased by nearly $3 \%$ in 2020 , ranked one of the fastestgrowing economies in the world, backed by the early rebound of domestic activities and robust export performance thanks to their drastic and appropriate actions.
\end{abstract}

Keywords: COVID-19 pandemic; Vaccination; Economic growth rate; Global economic shock; Economic activity; General policy

\section{Outbreak timeline overview in Vietnam}

Fig. 1 shows the number of confirmed in some countries, it is lower than the number of actual cases due to the limitation of testing. The number of new COVID-19 cases and deaths globally has been booming since the first reported in December 2019 in Wuhan, China, with 162,177,376 confirmed, including 3,364,178 deaths according to the report of WHO on May $16^{\text {th }}, 2021[1,2]$. The most severely affected countries include the U.S., Brazil, and India.

As of May 16, 2021, Vietnam had reported 4,242 cases of COVID-19 with 37 deaths, though 2,668 of the patients had recovered. The first case was reported on January 23, 2020, and Vietnam quickly formed a national steering committee that initially met every two days to coordinate the country's "whole of government" strategy a week later. They also locked down some communes, isolated patients and their close contacts in quarantine areas for at least 2 weeks, and performed the whole community screening at the early evidence of community spread. After a hundred days into the outbreak since the first reported case, Vietnam had confirmed just 270 cases, despite extensive testing, and with no community transmission since April 15.13 Vietnam began loosening restrictions in May, including resuming domestic travel across the country.

The new case has occurred in the city of Da Nang on July 25 $5^{\text {th }}, 2020$ after 99 days in Vietnam marked a period without any newly reported case. Da Nang was especially crowded at this time since people were eager for travelling after a tense spring, and the government encouraged domestic tourism as a way to compensate for the economic losses from international tourism. 551 locally cases were discovered from 15 cities and provinces across the country, affecting

\footnotetext{
${ }^{*}$ Corresponding author: Nguyen Thi Van Anh

Faculty of Business Management, Hanoi University of Industry, No 298 Cau Dien Street, Minh Khai Ward, Bac Tu Liem District, Hanoi City, Vietnam.

Copyright (C) 2021 Author(s) retain the copyright of this article. This article is published under the terms of the Creative Commons Attribution Liscense 4.0.
} 
seriously Da Nang and Quang Nam Province corresponding to approximately $98 \%$ of cases that were either related to these areas.

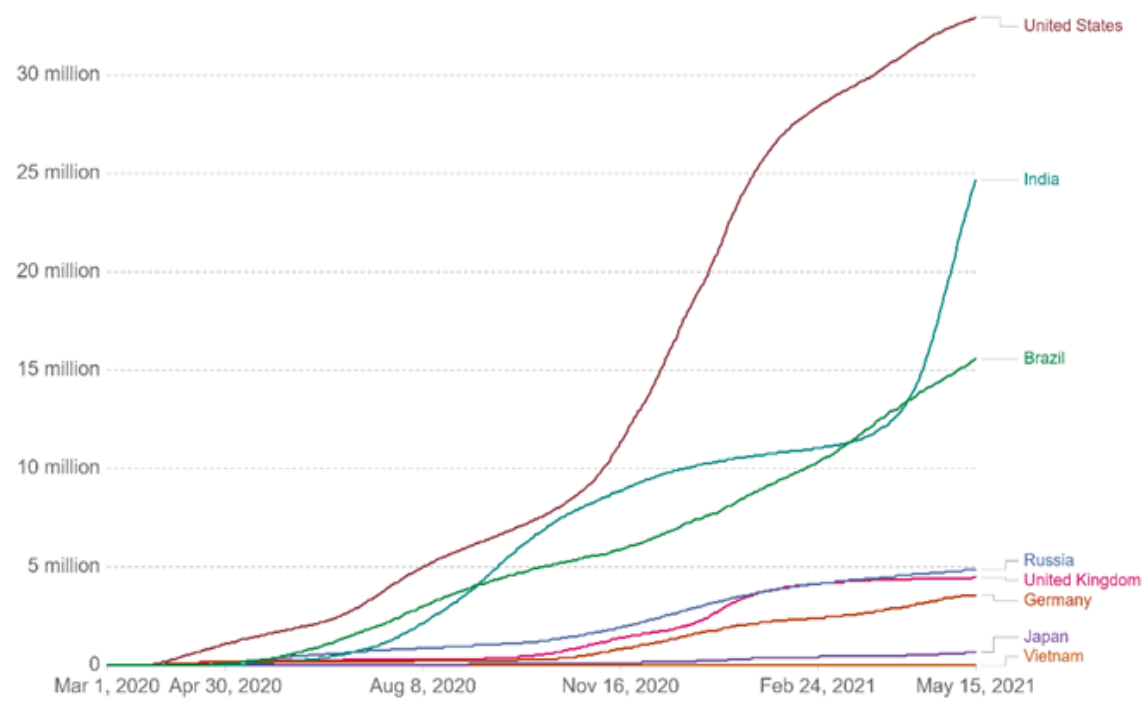

Figure 1 Total confirmed nCOV-2019 cases in some countries [1]

At the end of Jan 2021, the first community COVID-19 case in Chi Linh City located in Hai Duong Province was detected, she was a worker in close contact with a woman who tested positive for SARS-CoV-2 after travelling to Japan. The outbreak started at a company with more than 2000 workers and then spread to the community, which caused difficulties in determining the infections. The government issued immediately a directive ordering a 21-day lockdown in Chi Linh city, following the detection of major clusters of community COVID-19 cases. As the pandemic was gradually controlled, Hai Duong Province authorities decided to end the lockdowns and province-wide social distancing, entering a "new normal" phase with twin tasks of drastically fighting the coronavirus and acting for socio-economic development.

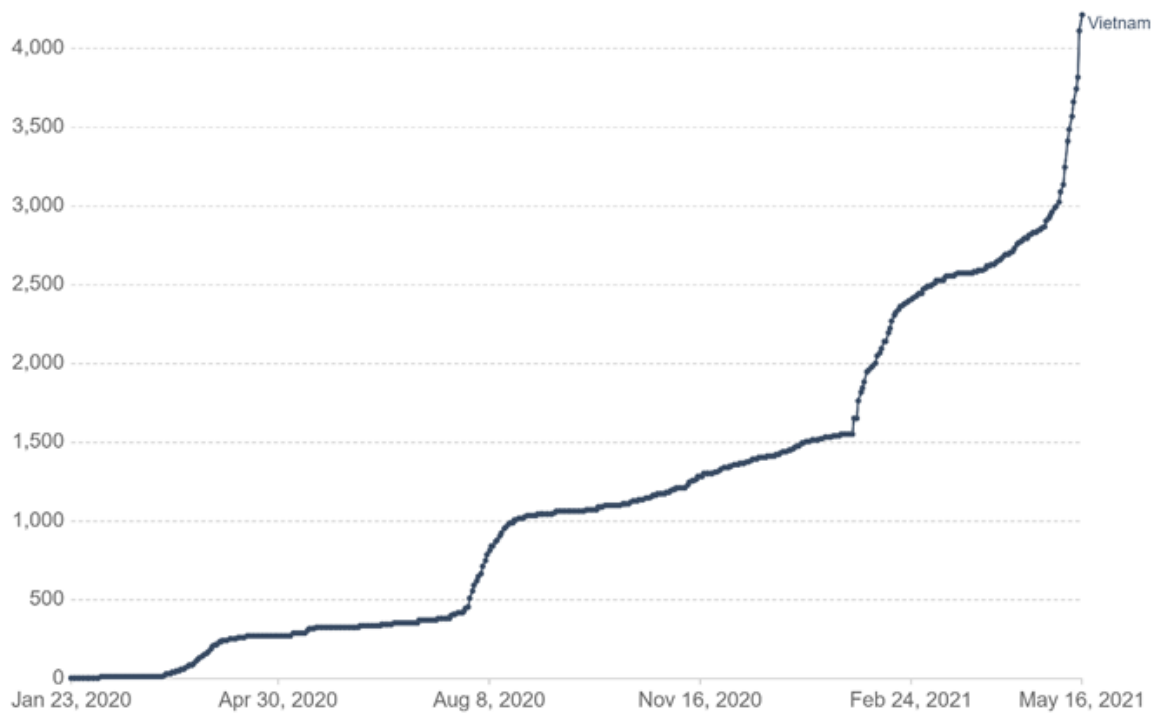

Figure 2 Total confirmed nCOV-2019 cases in Vietnam [1]

On May 15th, 2020, the Health Ministry confirmed 165 community transmissions in Hanoi, Da Nang and several northern provinces, raising the infection tally in its fourth coronavirus wave to approximately 1000 . To bring the outbreak under control, Vietnam turned to the same strategies that had been successful in ending earlier outbreaks: targeted lockdowns, travel bans, business closures, mass quarantines, and widespread testing. Vietnam has suspended the entry of all foreigners since March 22, 2020, until further notice to limit the spread of COVID-19. Vietnam's Ministry of Health extended the mandatory quarantine period to 21 days from the previous 14-day requirement from May 5 after several patients, who came from abroad, tested positive after completing the requirement. In addition, several non- 
essential services such as nightclubs, karaoke parlours, massage parlours, bars, movie theatres, and gyms in Hanoi, Ho Chi Minh City, Da Nang, Ha Nam, Vinh Phuc, and Quang Nam have been suspended.

\section{Economic Vietnam outlook during the COVID-19 pandemic}

The nCOV-2019 outbreak has negatively affected all countries in the world with critical consequences impacting all communities and individuals. It very quickly across borders, along the principal arteries of the world's economy, the spread of the virus has relied on the underlying interconnectedness of globalization, catapulting a global health crisis into a global crisis hitting the most vulnerable the hardest. According to the estimation of IMF, the global growth in 2020 is projected to be $-4.4 \%$, an upward revision of 0.8 percentage points in comparison with the June update. However, in 2021 growth is estimated to rebound to $5.2 \%,-0.2 \%$ points below the last update.

Although the n-COV-2019 has affected seriously throughout the country, Vietnam's economy remains stable, expanding by $2.9 \%$ in last year and listed one of the highest growth rates in the world and projected to be $6.5 \%$ in 2021 due to its strong economic fundamentals, decisive containment measures and well-targeted government support of the country's economy $[3,4]$.

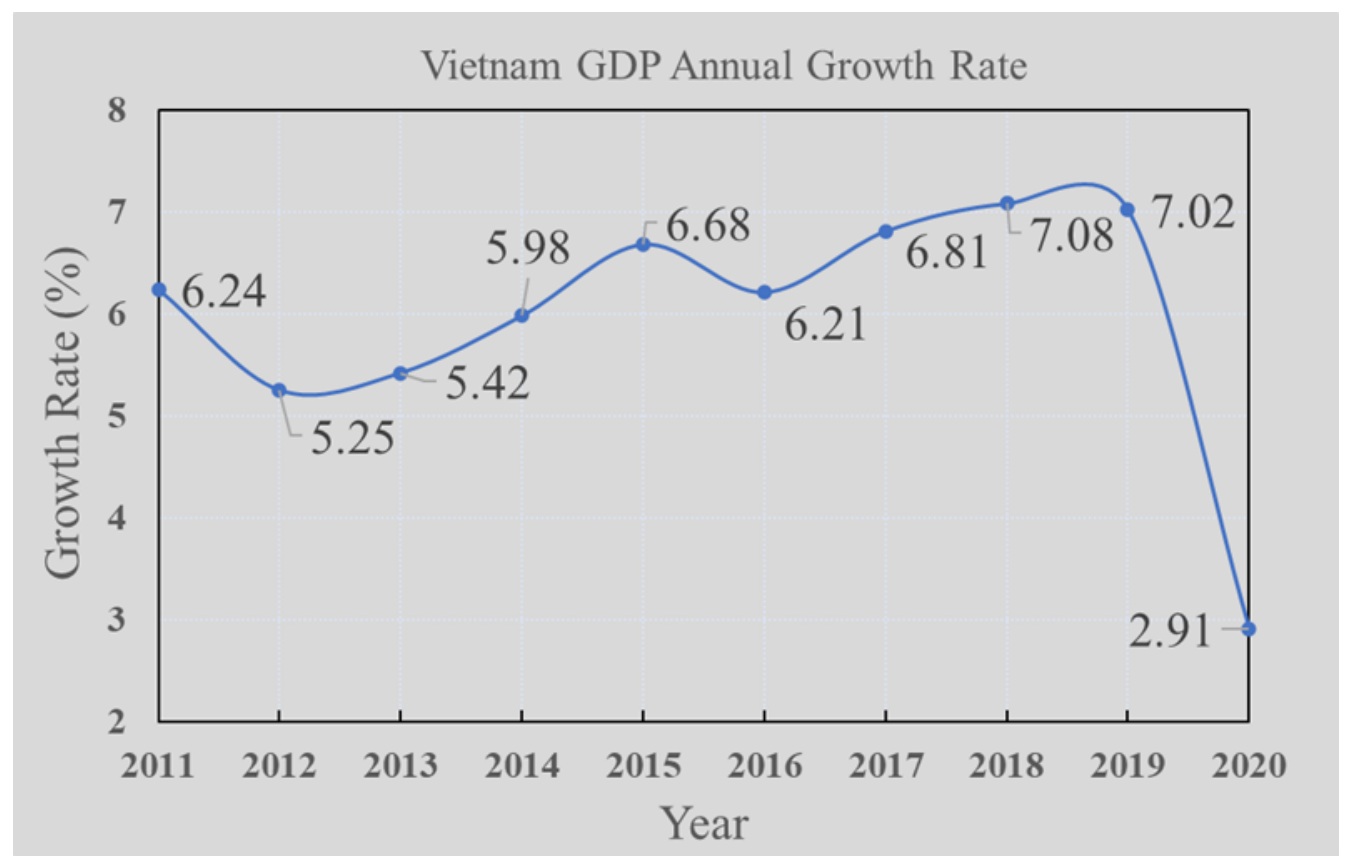

Figure 3 GDP growth rate in the period 2011-2020 [4]

Fig. 3 shows the GDP growth rate of Vietnam within recently 10 years. It can be observed that GDP in 2020 is the lowest and only $40 \%$ compared to 2019 . However, it is still very positive compared to other countries in the world. Vietnam's economy is expected to grow $6.6 \%$ in 2021 on the back of successful control of COVID-19 infections, strong performance by export-oriented manufacturing and robust recovery in domestic demand.

Vietnam's manufacturing sector was credited for the economy's outperformance in 2020, with productive growth of steady export demand and this trend will continue keeping in the following years according to the analysis of professional economists. As a result, it is estimated to increase by $3.36 \%$ over the previous year compared to 2020 (5.1\% in the first quarter, $1.1 \%$ in the second quarter, $2.34 \%$ in the third quarter, and $4.80 \%$ in the fourth quarter). In which, the processing and manufacturing sector increased by $5.82 \%$ corresponding to $1.25 \%$ to the overall growth of the whole economy. Furthermore, electricity production and distribution increased by 3.92\%, contributing $0.19 \%$ points; water supply, waste and wastewater treatment and management activities increased by $5.51 \%$. However, the mining sector decreased by $5.62 \%$ (due to a $12.6 \%$ decrease in crude oil production and a decrease of $11.5 \%$ ), reducing $0.36 \%$ points in the overall increase.

According to a general report, despite the negative impact of the Covid-19 epidemic, the disease, floods and critical weather in the northern mountainous area, the whole agricultural sector still achieved positive results. Specifically, the GDP growth rate of the whole agricultural sector is about 2.65\%; total export turnover was 41.25 billion USD; rural 
income reached 1,800 USD/person [5]. In general, the agricultural sector still ensures food for the people in Vietnam. Vietnam can still guarantee 43 million tons of rice, export 6 million tons of rice. Exports surpassed 41 billion USD for the first time, generating over 10 billion USD in trade surplus, accounting for about $50 \%$ of Vietnam's total trade surplus in 2020. Furthermore, experts believe that Vietnam has great opportunities to develop hi-tech agriculture, promote farmer to become traders to promote their products via online channels. This is one of the factors that need to be promoted for agriculture to maintain its supporting role in the economy.

For the service sector, total retail sales of consumer goods and services decreased by $1.2 \%$ in the first 6 months of 2020 compared to the same last period; it recovered markedly in the last 6 months, and reached $6.2 \%$, bringing the domestic trade sector up 2.6\% for the whole year. The growth rates of some market service sector are as follows: Wholesale and retail increased by $5.53 \%$ over the previous year, contributing $0.61 \%$ points; financial, banking and insurance activities increased by $6.87 \%$, contributing $0.46 \%$ points; the transportation and warehousing industry decreased by $1.88 \%$, decreasing by $0.06 \%$ points; accommodation and catering services decreased by $14.68 \%$, down $0.62 \%$ points.

\section{Conclusion}

According to the mid-2021 report of World Economic Situation and Prospects, following a sharp contraction of 3.6\% in 2020 , the global economy is now projected to expand by $5.4 \%$ in 2021 . Vietnam's economy maintained a growth rate of $2.9 \%$ in 2020 and is forecast to reach $6 \%$ in 2021 due to the successful control of COVID-19 infections, strong performance by export-oriented manufacturing and robust recovery in domestic demand. Besides the above advantages, Vietnam's economy has still faced many difficulties due to the fluctuations of the world economy. Although the Covid-19 has been controlled well in Viet Nam, it's still complicated leading to the delay in production, supply and circulation trade, aviation, tourism, labour and employment. Consequently, Vietnam needs to focus on implementing the dual goal of both reducing diseases and recovering and developing socio-economic in a new normal state. In addition, at the same time, it needs to maximize potentials and advantages to bring the economy to the highest growth rate in the following years.

\section{Compliance with ethical standards}

\section{Acknowledgments}

This research was support by the Faculty of Business Management, Hanoi University of Industry

\section{Disclosure of conflict of interest}

There are no conflicts of interest regarding the publication of this paper

\section{References}

[1] COVID-19 Data Explorer, https://ourworldindata.org/covid-overview. Access date: 10th, May 2020.

[2] WHO Coronavirus (COVID-19), Dashboard, https://covid19.who.int. Access date: 10th, May 2020.

[3] Vietnam: Successfully Navigating the Pandemic, https://www.imf.org/en/News/Articles/2021/03/09/na031021-vietnam-successfully-navigating-thepandemic. Access date: 10th, May 2020.

[4] The Global Economic Outlook During the COVID-19 Pandemic: A Changed World, the world bank report, https://www.worldbank.org/en/news/feature/2020/06/08/the-global-economic-outlook-during-the-covid19-pandemic-a-changed-world. Access date: 10th, May 2020.

[5] Viet Nam economy in 2020 the growth of a year with full of bravery, the report of general statistics office of Vietnam, https://www.gso.gov.vn/en/data-and-statistics/2021/01/viet-nam-economy-in-2020-the-growth-ofa-year-with-full-of-bravery. Access date: 10th, May 2020. 